\title{
Reconciling aerosol light extinction measurements from spaceborne lidar observations and in situ measurements in the Arctic
}

\author{
M. Tesche ${ }^{1}$, P. Zieger ${ }^{1}$, N. Rastak ${ }^{1}$, R. J. Charlson ${ }^{2}$, P. Glantz ${ }^{1}$, P. Tunved ${ }^{1}$, and H.-C. Hansson ${ }^{1}$ \\ ${ }^{1}$ Department of Applied Environmental Science, Stockholm University, Stockholm, Sweden \\ ${ }^{2}$ Department of Atmospheric Sciences, University of Washington, Seattle, WA 98195, USA \\ Correspondence to: M. Tesche (matthias.tesche@itm.su.se)
}

Received: 10 February 2014 - Published in Atmos. Chem. Phys. Discuss.: 4 March 2014

Revised: 11 June 2014 - Accepted: 1 July 2014 - Published: 8 August 2014

\begin{abstract}
In this study we investigate to what degree it is possible to reconcile continuously recorded particle light extinction coefficients derived from dry in situ measurements at Zeppelin station $\left(78.92^{\circ} \mathrm{N}, 11.85^{\circ} \mathrm{E} ; 475 \mathrm{~m}\right.$ above sea level), Ny-Ålesund, Svalbard, that are recalculated to ambient relative humidity, as well as simultaneous ambient observations with the Cloud-Aerosol Lidar with Orthogonal Polarization (CALIOP) aboard the Cloud-Aerosol Lidar and Infrared Pathfinder Satellite Observations (CALIPSO) satellite. To our knowledge, this represents the first study that compares spaceborne lidar measurements to optical aerosol properties from short-term in situ observations (averaged over $5 \mathrm{~h}$ ) on a case-by-case basis. Finding suitable comparison cases requires an elaborate screening and matching of the CALIOP data with respect to the location of Zeppelin station as well as the selection of temporal and spatial averaging intervals for both the ground-based and spaceborne observations. Reliable reconciliation of these data cannot be achieved with the closest-approach method, which is often used in matching CALIOP observations to those taken at ground sites. This is due to the transport pathways of the air parcels that were sampled. The use of trajectories allowed us to establish a connection between spaceborne and groundbased observations for 57 individual overpasses out of a total of 2018 that occurred in our region of interest around Svalbard $\left(0\right.$ to $25^{\circ} \mathrm{E}, 75$ to $\left.82^{\circ} \mathrm{N}\right)$ in the considered year of 2008 . Matches could only be established during winter and spring, since the low aerosol load during summer in connection with the strong solar background and the high occurrence rate of clouds strongly influences the performance and reliability of CALIOP observations. Extinction coefficients in the range of 2 to $130 \mathrm{Mm}^{-1}$ at $532 \mathrm{~nm}$ were found for successful matches
\end{abstract}

with a difference of a factor of 1.47 (median value for a range from 0.26 to 11.2) between the findings of in situ and spaceborne observations (the latter being generally larger than the former). The remaining difference is likely to be due to the natural variability in aerosol concentration and ambient relative humidity, an insufficient representation of aerosol particle growth, or a misclassification of aerosol type (i.e., choice of lidar ratio) in the CALIPSO retrieval.

\section{Introduction and motivation}

Understanding and quantifying the climatic effects of natural and anthropogenic aerosols from direct observations requires a combination of data from a variety of instruments that usually apply very different measurement techniques. For example, ground-based in situ measurements of aerosol optical, microphysical, and chemical properties (that are usually carried out with very high temporal resolution but only at a limited number of locations) can be combined with satellite observations or aircraft measurements (that generally provide us with better spatial data coverage but are limited in temporal resolution and/or detail). The combination of such data needs to overcome differences in measurement time, location, and measured quantity. This poses the fundamental problem of relating point-sampling data to either spatially resolved data with poor temporal coverage or airborne measurements without profile information. Four issues arise:

1. Differences in measurement techniques: different properties of the aerosols are sensed or observed by the various instruments. Satellite observations usually are based on optical properties, while in situ measurements can 
be of optical properties as well as physical and chemical properties that can be transformed via theory or empirical data (i.e., parameterization) to optical properties (and vice versa).

2. Spatial resolution: location and spatial resolution of the aerosol measurements are different. In situ observations are often point measurements, while the swath width of passive satellite sensors can extend over up to a few thousand kilometers. In addition, active satellite sensors with narrow footprints often do not cover exactly the location where the in situ observations are performed. It can also happen that clouds obstruct the wide field of view of a spaceborne sensor. If the satellite data were taken at a distance away from the ground site, it is also necessary to consider the time difference as a lead or a lag of timing.

3. Hygroscopicity: the thermodynamic state of the air (especially the relative humidity, $\mathrm{RH}$ ) has a strong effect on the aerosol optical properties (particularly in the lower marine troposphere) and is different for the different observations. Remote sensing of aerosols is normally performed under ambient conditions (i.e., within the atmosphere), while most in situ instruments sample the aerosol under dry conditions with $\mathrm{RH}<30-40 \%$ (WMO, 2003).

4. Temporal resolution: the time periods over which the observations are averaged may be various. Short temporal averages (i.e., a few hours) complicate a comparison since such an effort is only meaningful when the different sensors actually observe the same air mass. Longterm averages (i.e., monthly means), on the other hand, can generate arbitrary coherence of the data - especially when the considered data sets are of different size.

It is necessary to utilize these simultaneous but disparate data to be able to perform a closure study for the validation of remote-sensing data with independent in situ measurements and vice versa. Such closure studies are important not only for validating the retrievals of aerosol optical thickness (AOT) or the aerosol extinction coefficient but also for investigating how the measured quantities are apportioned to different types of aerosol, e.g., how large the anthropogenic influence is on the optical properties of the atmosphere and thus the radiation balance. For this we have to be able to demonstrate that the measurement systems actually are sensing the same entity. The practical reality (i.e., it is not a simple matter to combine the in situ and satellite data) is made into a doable but challenging task by recognition at the outset that both the spaceborne and the in situ instrument are well-tested devices that are operating correctly within the scope of their capabilities. Thus, the effort described here is not the usual ground truth sort of activity done in order to constrain measurement uncertainties. Rather, we intend to devise methods to bring the data sets into concordance.
Here, we consider in situ measurements performed at the Arctic station at Mt. Zeppelin $\left(78.92^{\circ} \mathrm{N}, 11.85^{\circ} \mathrm{E} ; 474 \mathrm{~m}\right.$ above sea level), Svalbard, in comparison with data taken simultaneously (or nearly so) with the Cloud-Aerosol Lidar with Orthogonal Polarization (CALIOP) aboard the CloudAerosol Lidar and Infrared Pathfinder Satellite Observations (CALIPSO; Winker et al., 2009) satellite. CALIPSO is operating in near-polar orbit at an altitude of about $705 \mathrm{~km}$.

In situ instruments usually measure aerosol properties under dry conditions with a RH of 10-30\% in an indoor laboratory, while ambient conditions are usually associated with a much higher RH of up to $100 \%$. Hence, in situ measurements need to be transformed to ambient conditions by means of direct RH-dependent measurements or a microphysical particle model to account for the loss in particle size due to drying the aerosol particles (Tang and Munkelwitz, 1994; Tang, 1996; Zieger et al., 2013). On the other hand, ambient aerosol extinction coefficients can be measured directly, for instance with active optical remote-sensing techniques such as lidar or differential optical absorption spectroscopy (DOAS). Previous closure studies have shown that reasonable agreement is found between results obtained from remote sensing of aerosols and findings from in situ observations when the effect of relative humidity has been accounted for (Hoff et al., 1996; Masonis et al., 2002; Zieger et al., 2011, 2012; Hoffmann et al., 2012; Ziemba et al., 2013; Skupin, 2014). However, studies in the literature mainly deal with a few single cases during intensive field campaigns rather than systematic comparisons of multiyear data sets.

The clean environment of the Arctic is very sensitive to anthropogenic impacts. Arctic aerosol conditions are also strongly influenced by regional meteorology (Eneroth et al., 2003; Stock, 2014), which controls the RH of the air. Changes in this parameter have a huge influence on aerosol particle size and thus light scattering (Zieger et al., 2010, 2013) and cloud formation (Mauritsen et al., 2011) in this region. Optical properties and concentrations of Arctic aerosols have been measured at Ny-Ålesund, Svalbard, with in situ instruments (Covert and Heintzenberg, 1993; Ström et al., 2003; Tunved et al., 2013) and by means of remote sensing (Herber et al., 2002; Hoffmann et al., 2009, 2012; Tomasi et al., 2007, 2012) for several years.

Hoffmann et al. (2012) performed a combined analysis of ground-based Raman lidar measurement at Ny-Ålesund and in situ measurements at Zeppelin station. Instead of the aerosol extinction coefficient, they compare the particle number concentration as obtained from a microphysical inversion of the lidar data and measured by the in situ instruments. As the ground-based lidar data cannot be used to derive aerosol optical properties below $750 \mathrm{~m}$ height accurately, measurements at Zeppelin station ( $474 \mathrm{~m}$ height) were instead compared to lidar findings obtained at a height of $850 \mathrm{~m}$. Despite the elaborate comparison approach (e.g., different heights, assumptions in the inversion of lidar data), the total aerosol number concentration for the investigated pollution event on 
4 April 2009 could be reconciled to a factor of ca. 2 with smaller lidar-derived values compared to the in situ measurements.

The use of the spaceborne CALIPSO lidar has the potential to overcome the altitude limitations since its observations extend all the way down to the Earth's surface. The high frequency of overpasses at high latitudes makes it attractive to consider the possibility of a combined analysis of ground-based in situ and spaceborne lidar measurements in the Arctic. In principle, such an analysis connects information on the vertical and horizontal aerosol distribution from the CALIPSO satellite data to the more specific information about aerosol microphysical and chemical properties at the surface. In situ measurements are limited to a few measurement locations, while satellites can (in principle) view the exact same volume of air that is being sampled at the surface. Satellite sensors also have vastly larger fields of view and allow for global or near-global data coverage. Consequently, they have a strong potential to extend the findings of in situ measurements in space besides giving information on aerosol optical properties. In the same way, findings from detailed in situ measurements can add further depth to the satellite observations.

Di Pierro et al. (2013) used these advantages to perform a comprehensive study of the spatial and seasonal distribution of Arctic aerosols based on optical properties observed by CALIOP between 2006 and 2012. The authors introduce an empirical correction that accounts for the different measurement sensitivity during day and night - a crucial factor when it comes to summertime CALIOP observations in the Arctic. The authors found CALIOP aerosol extinction in the Arctic to be on the same order of magnitude as nephelometer observations at Barrow and Alert, with the latter being transformed to ambient RH. However, in addition to using highly averaged data (i.e., monthly and seasonal mean values) the averaging methodology of Di Pierro et al. (2013) applies a detection frequency that is defined as the ratio of the number of height bins with detected aerosol layers to the total number of height bins in a given area and time period. This procedure is likely to decrease the magnitude of the obtained mean extinction profiles by introducing zero-values into the averaging. In fact, the authors show that the mean CALIOP extinction profile obtained for a comparison to measurements with a high-spectral-resolution lidar (HSRL) at Eureka yields much smaller values than the ground-based HSRL observations. Di Pierro et al. (2013) also provide the reader with the seasonal variation of CALIOP-derived mean extinction coefficients for different atmospheric layers. Their values for the layer from the surface to $2 \mathrm{~km}$ height are a maximum at around $10 \mathrm{Mm}^{-1}$ in March for the Atlantic sector which is most representative of the conditions at Svalbard. This relates to a maximum AOT of 0.02 for the polluted spring season if we assume that the majority of aerosols are present within this $2 \mathrm{~km}$ deep layer. Such a value is similar to what is observed in the Arctic troposphere around Svalbard during the clean summer season (Glantz et al., 2014). Note that it is more likely that the aerosol-containing planetary boundary layer at Svalbard is between 0.5 and $1.0 \mathrm{~km}$ deep - which would decrease the maximum AOT as derived from the values presented in Di Pierro et al. (2013) even further. This discrepancy calls for a more detailed investigation of the factors that influence the reconciliation of extinction coefficients from ground-based and spaceborne observations. We will return to this point in the conclusion.

A description of the instrumentation and the data processing used in this study is presented in Sect. 2. Section 3 describes the methodology for relating segments of individual CALIPSO overpasses to in situ measurements at Zeppelin station. The findings of the comparison for the year 2008 are discussed in Sect. 4. The paper ends with a summary and conclusions in Sect. 5.

\section{Instrumentation and methods}

\subsection{In situ measurements at Zeppelin station}

The aerosol in situ instruments at Zeppelin station include a differential mobility particle sizer (DMPS), for measuring the particle size distribution in the mobility diameter range from 10 to $790 \mathrm{~nm}$ (time resolution of $20 \mathrm{~min}$ ); a particle soot absorption photometer (PSAP) for measurements of particle light absorption coefficients at $525 \mathrm{~nm}$ (time resolution of $60 \mathrm{~min}$ ) on a filter; and an integrating nephelometer (TSI model 3563) for measurements of particle light-scattering coefficients at the wavelengths of 450,550, and $700 \mathrm{~nm}$ (time resolution of $10 \mathrm{~min}$ ) (Ström et al., 2003; Tunved et al., 2013). The nephelometer measurements were corrected for the truncation error and lamp non-idealities according to Anderson et al. (1998). All in situ instruments are placed indoors and connected to an inlet without a particle size cut.

The location of Zeppelin station at $79^{\circ} \mathrm{N}$ imposes a severe climatic situation, with usually low outside temperature (from -25 to $+15^{\circ} \mathrm{C}$ ) and correspondingly high $\mathrm{RH}$, often near or at $100 \%$. The in situ instruments in the laboratory are operated at an ordinary room temperature of about $20^{\circ} \mathrm{C}$. Hence, sampled air is heated by as much as $40 \mathrm{~K}$ during its transit into the laboratory. Continuous aerosol in situ observations are usually performed under dry conditions with $\mathrm{RH}<30-40 \%$ in order to avoid the influence of water uptake on the aerosol optical properties and to keep the measurements at different ambient RH and at different sites comparable (WMO, 2003). The humidity effect on the scattering properties of the aerosol has to be accounted for if results are to represent actual atmospheric conditions.

A high-volume sampler with a PM10 inlet was used to obtain the chemical composition of the Arctic aerosol with time resolutions of 1 day for sulfate and sea salt and 1 month for OC / EC during 2008. 
Measurements with a humidified nephelometer operating at RH between 20 and $95 \%$ were carried out between 15 July 2008 and 12 October 2008 at Zeppelin station (Zieger et al., 2010). A comparison to Zeppelin's dry nephelometer (operating at $\mathrm{RH}<20 \%$ ) showed that the ambient scattering coefficients at $\mathrm{RH}=85 \%$ were on average about 3 times higher than the scattering coefficients of the dried aerosol sample (Zieger et al., 2013). Direct measurements of the scattering enhancement factor were only available for 91 days in 2008 .

\subsection{Transferring measured dry parameters to ambient conditions}

Hourly measurements of outdoor humidity at Zeppelin station are available to transform the dry in situ measurements to ambient conditions. This is done following two approaches by using (1) the chemical composition of the particles in combination with the particle size distribution from the DMPS as input to a hygroscopicity model and (2) the direct measurements of scattering and absorption coefficients from the nephelometer and PSAP in combination with a scattering enhancement factor $f(\mathrm{RH})$. Cases with ambient $\mathrm{RH}$ larger than $95 \%$ were considered to be measurements within clouds or fog and were thus excluded from the procedure.

\subsubsection{Site-specific hygroscopicity model}

Dry size distributions are transformed to ambient conditions and then used as input for a Mie-scattering model to obtain ambient aerosol optical properties. For a detailed description of this procedure we refer the reader to Rastak et al. (2014), but a brief summary is given here.

Hygroscopicity effects are accounted for with the help of $\kappa$-Köhler theory (Kreidenweis et al., 2005; Petters and Kreidenweis, 2007). The aerosol growth factor is derived by combining the individual aerosol volume fractions obtained from the analysis of chemical samples collected at Ny-Ålesund with the hygroscopicity parameter $\kappa$ of the respective components available in the literature. The components considered in this study are water-soluble and insoluble organics, ammonium sulfate, sea salt, and black carbon.

Ambient aerosol scattering, absorption, and extinction coefficients are obtained from the humidified aerosol size distribution and refractive index by means of Mie-scattering theory. All optical properties are calculated at a wavelength of $550 \mathrm{~nm}$ and with a temporal resolution of $1 \mathrm{~h}$. Note that absorption contributes less than $5 \%$ to the ambient extinction coefficient of Arctic aerosols (Eleftheriadis et al., 2009; Zieger et al., 2010). This is in agreement with the PSAP measurements at Zeppelin. The effect of light absorption decreases even further when ambient extinction coefficients are considered. The uncertainties of a misrepresentation of aerosol light absorption become negligible when put into the context of the challenges imposed by the comparison procedure described in Sect. 3.

A validation of the microphysical model is presented in Rastak et al. (2014). Dry aerosol scattering coefficients measured by the nephelometer agree with those calculated from the particle size distributions (slope close to unity, $R^{2}=$ 0.95). A comparison between humidified scattering coefficients and measurements with the humidified nephelometer during the 91 days of parallel operation (Zieger et al., 2010) showed a slight tendency of the model to underestimate the measurements with $R^{2}=0.64$ (Rastak et al., 2014). The enhancement factor $f(\mathrm{RH})$ is the ratio of ambient to dry extinction coefficients. Values of $f(\mathrm{RH})=4.30 \pm 2.26$ with a range from 1.5 to 12.5 were found when relating the results obtained from the humidified size distribution to the dry nephelometer measurements for the year 2008. This is in agreement with the findings of Zieger et al. (2010) for Arctic aerosols at ambient $\mathrm{RH}$ at Zeppelin station.

The humidification of the particle number size distribution obtained with the DMPS leads to an increase of the particle effective (surface-weighted) radius from $0.14 \pm 0.02$ to $0.23 \pm 0.04 \mu \mathrm{m}$ (yearly average, not shown). This moves the aerosol from an optically ineffective state to a size range in which they are more efficient in interacting with visible light. Contributions of particles larger than the maximum DMPS size bin would lead to an overall increase in the effective radius and thus would further improve the light-scattering efficiency of the probed aerosol.

\subsubsection{Dry aerosol optical measurements and range of observed $f(\mathbf{R H})$}

The DMPS measurements used in the previous section only cover particles up to a diameter of $790 \mathrm{~nm}$ and provide no information on the concentration of larger particles. Particles in the coarse mode can have a large effect on the overall extinction coefficient due to their size and increased extinction efficiency, although their concentration might be very low. Hence, missing even low concentrations of coarse particles can cause an underestimation of the aerosol scattering and extinction coefficients by as much as $30 \%$. In addition, it is more straightforward to determine ambient extinction coefficients directly from the nephelometer measurements if the scattering enhancement factor is known or can be estimated within a reasonable range of values.

Therefore, ambient extinction coefficients were also calculated using the dry absorption and scattering coefficients measured with the PSAP and nephelometer, respectively, together with scattering enhancement factors that represent the median, minimum, and maximum effect of hygroscopic growth on light scattering. Values of $\gamma=0.57,0.35$, and 0.85 , respectively, were used to obtain the scattering enhancement factor for ambient RH as $f(\mathrm{RH})=(1-\mathrm{RH})^{-\gamma}$ (Zieger et al., 2010). Absorption coefficients were assumed not to change with increasing $\mathrm{RH}$. 


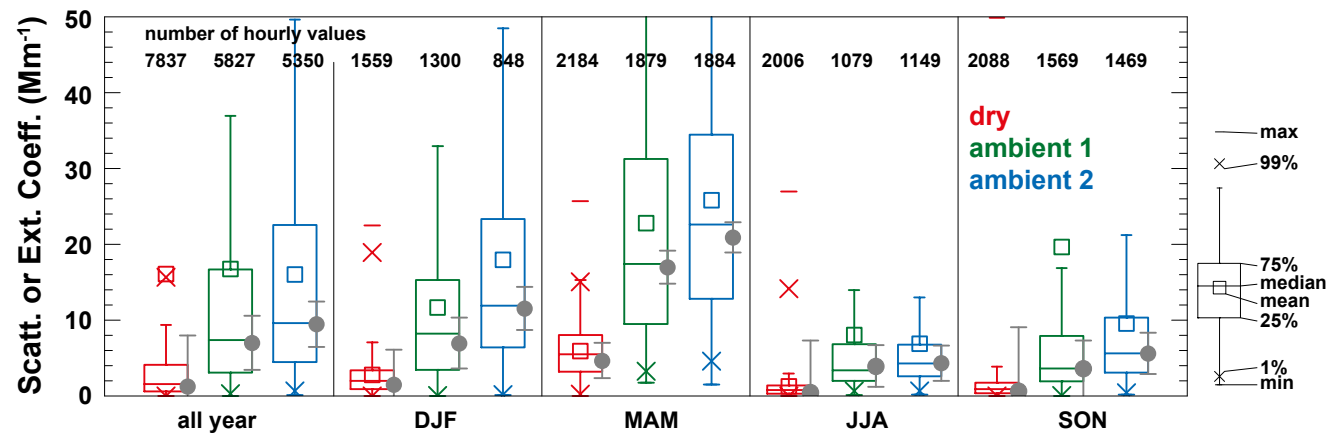

Figure 1. Statistical overview of the dry scattering (red) and ambient extinction coefficients at 550 nm based on hourly measurements at Zeppelin station in 2008 according to the entire year and the different seasons: winter (DJF), spring (MAM), summer (JJA), and fall (SON). The ambient extinction coefficients refer to the results obtained by using humidified size distributions from DMPS measurements in combination with Mie-scattering theory (ambient 1, green) and the dry nephelometer and PSAP measurements in combination with a scattering enhancement factor derived for a mean $\gamma$ of 0.57 (ambient 2, blue). The numbers at the top of the figure mark the number of available hourly measurements. The difference in data availability for dry scattering and ambient extinction coefficients is the consequence of cloud screening and an absence of input data required for humidity correction.

\subsubsection{Dry vs. ambient optical properties}

The box plots in Fig. 1 show the importance of transforming dry optical properties to ambient conditions. About $75 \%$ of the hourly aerosol scattering coefficients at $550 \mathrm{~nm}$ measured with the dry nephelometer at Zeppelin station in 2008 are smaller than $5 \mathrm{Mm}^{-1}$. Humidity correction to ambient extinction coefficients increases the median value for 2008 from 2 to $7-10 \mathrm{Mm}^{-1}$. The differences found in the median values of the ambient extinction coefficients derived according to the two methods described in Sects. 2.2.1 and 2.2.2 is likely to be the effect of coarse-mode particles that are not captured by the DMPS. These particles may contribute to about $20-30 \%$ of the total extinction coefficient at Zeppelin station (Zieger et al., 2010). The geometric mean has a much lower standard deviation than the arithmetic mean and is similar to the arithmetic median value. Independent of the retrieval method, the ambient extinction coefficient is on average a factor of 3 to 5 larger than the dry one when resolved according to different seasons. The Arctic haze period in spring shows the highest median values of the ambient extinction coefficient $\left(17-22 \mathrm{Mm}^{-1}\right)$, followed by winter $\left(8-12 \mathrm{Mm}^{-1}\right)$. Summer and fall are associated with very low median values (3-4 and $4-6 \mathrm{Mm}^{-1}$, respectively). Summer is the slightly cleaner season, and a larger variation is observed during fall. This is in agreement with previous observations at Zeppelin station (Ström et al., 2003; Zieger et al., 2010; Tunved et al., 2013).

In the following, we use the ambient extinction coefficients derived from the humidified nephelometer measurements. This is because the lower and upper estimate in the $\gamma$ value for the determination of the scattering enhancement provides an uncertainty range that is more reliable than what can be obtained using the model approach described in Sect. 2.2.1.

\subsection{CALIOP}

The CALIOP is an elastic-backscatter lidar that emits linearly polarized laser light at 532 and $1064 \mathrm{~nm}$ wavelength and features three measurement channels. It has been operational since June 2006. An overview of the instrument as well as the data retrieval and interpretation algorithms can be found, for example, in Winker et al. (2009), Young and Vaughan (2009), and Omar et al. (2009).

\subsubsection{Data treatment}

For the comparison presented here we use level 2, version 3.01 products with a vertical resolution of $60 \mathrm{~m}$ (below $20.2 \mathrm{~km}$ height) and a horizontal resolution of $5 \mathrm{~km}$. To derive extinction coefficients for comparison, we only considered CALIPSO profiles with Atmospheric_Volume_Description bits 1-3 equal to 3 (feature type $=$ aerosol), a CAD_Score below -20 (screen artifacts from data), and an Extinction_QC_Flag_532 of either 0 or 1. A description of the CALIPSO lidar level $25 \mathrm{~km}$ cloud and aerosol profile and layer products can be found in the CALIPSO Users Guide (2012).

Retrieving extinction coefficients from CALIOP observations requires the assumption of an aerosol-type-specific extinction-to-backscatter (lidar) ratio (Müller et al., 2007; Omar et al., 2009). The CALIPSO aerosol model distinguishes between six aerosol types that are selected according to the location of the instrument (surface type) and the detected feature (aerosol layer close to surface or elevated), the intensity of the measured signal (integrated attenuated backscatter coefficient), and an approximated value of the aerosol depolarization ratio (Omar et al., 2009). The considered aerosol types are clean marine, dust, polluted continental, clean continental, polluted dust, and smoke. The lowest 
$532 \mathrm{~nm}$ lidar ratio of $20 \mathrm{sr}$ is that of clean marine aerosol, while the highest values of 65 and $70 \mathrm{sr}$ are used for polluted mineral dust, polluted continental aerosol, and biomassburning smoke. Background conditions are described by the clean continental type, which features a lidar ratio of $35 \mathrm{sr}$. Lidar ratios of $30-40 \mathrm{sr}$ at $532 \mathrm{~nm}$ are reported by Hoffmann et al. (2012) and Stock (2012) for two cases at NyÅlesund during spring 2009 and 2008, respectively. Proper aerosol-type identification is crucial for accurate extinctioncoefficient retrievals due to the wide range of available lidar ratios (Müller et al., 2007). Details regarding the CALIPSO lidar-ratio selection algorithm are presented in Omar et al. (2009).

\subsubsection{Representativeness}

To assess the representativeness of the CALIOP measurements in our region of interest around Svalbard, it is worthwhile first examining the availability of lidar profiles and the atmospheric conditions (i.e., the abundance of aerosols and clouds) encountered during these observations. Figure 2a shows the number of monthly available lidar profiles subdivided according to what has been detected in the individual profiles: no features (neither clouds nor aerosols), only aerosols (aerosol features but no cloud features in a profile), only clouds (cloud features but no aerosol features in a profile), or clouds and aerosols (both cloud and aerosol features in a profile). For the entire year of 2008 , only $5.8 \%$ of the considered 187711 profiles show conditions of aerosols only (i.e., no disturbance by clouds) that are most favorable for the type of comparison that we pursue in this study. Best conditions are found during March $(15.1 \%$ cloud-free profiles with aerosols features), while the summer months (May to September), particularly July ( $0.6 \%$ cloud-free profiles with aerosol features), represent non-ideal conditions for the comparison of surface measurements and spaceborne observations attempted in this study. About $10 \%$ of all CALIOP profiles contain neither aerosol nor cloud features with a maximum and minimum occurrence rate of 25 and $4 \%$ in July and January, respectively. This effect is due to the weaker signalto-noise ratio (SNR) of CALIOP measurements during bright daytime conditions (i.e., polar summer) compared to the absence of sunlight during night and the correspondingly higher threshold value that has to be exceeded for feature detection (Winker et al., 2009; Young and Vaughan, 2009). Polar summer and winter can be recognized in the occurrence rate of no features (magenta bars) in Fig. 2a. Observation rates of 50 to $85 \%$ for clouds only (during March and August, respectively) illustrate that cloudiness is another main obstacle for deriving aerosol information from CALIOP measurements. Most of these clouds are optically thick and lead to significant or full attenuation of the laser light. As long as these clouds form the uppermost feature, no aerosol detection is possible, even if cloud and aerosol layers are present at different height levels.
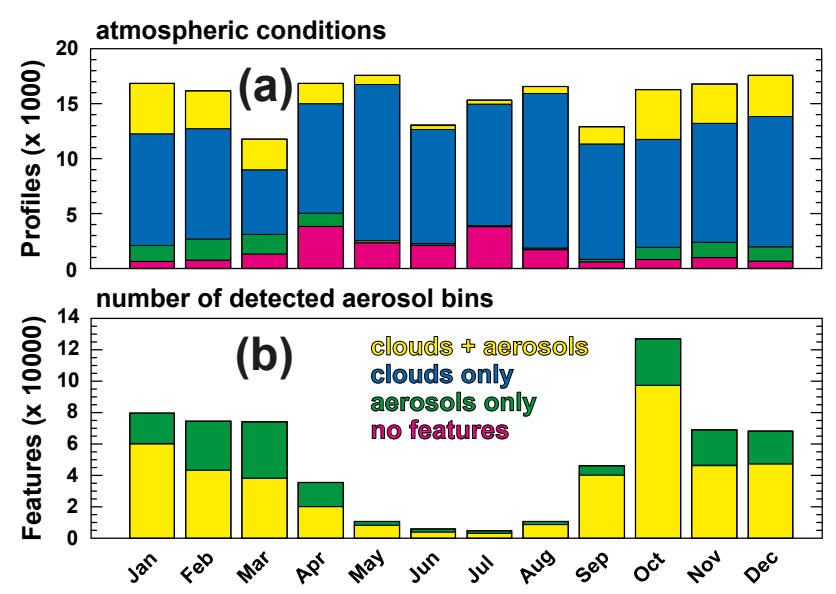

Figure 2. Histograms of the monthly abundance of (a) CALIOP level $25 \mathrm{~km}$ aerosol profiles and (b) $60 \mathrm{~m}$ height bins with aerosol observations as detected during 2018 CALIPSO overpasses in the region of interest during 2008. The color coding refers to the observed occurrence of atmospheric features (aerosols and/or clouds).

Figure $2 b$ shows the occurrence rate of the number of height bins with aerosol information for profiles that fall into the categories "aerosol only" and "clouds and aerosols" (i.e., profiles identified to contain aerosol information). Note that the information given in Fig. 2a refers to the entire profile whereas Fig. $2 b$ refers to the height-resolved observation provided by these profiles. Figure $2 \mathrm{~b}$ shows that the detection rate of aerosol bins (i.e., the amount of aerosolcontaining height bins per profile per month) is much higher during winter, when the background of sunlight is absent and clouds are also less frequent. During summer, almost no aerosol features are detected. This is probably due to the decreased SNR of the measurement during daytime, the generally cleaner conditions during this time of the year, or a combination of both. It is also apparent from Fig. 2b that most aerosol features are detected in combination with clouds in the same profile (yellow) rather than during cloud-free conditions (green). Looking at the number of detected aerosol layers given in the CALIPSO products reveals that aerosols occur within a single layer during the majority of observations (not shown). Multiple aerosol layers are only detected during polar night. The observation of two layers is already rare, and the number of cases with four layers is negligible.

To summarize Fig. 2, we can conclude that obtaining useful results from CALIOP measurements in the Arctic during summer is improbable and that only a very small fraction of all measurements will occur during cloud-free conditions that are favorable for the kind of study we attempt to perform in this paper. Attempts to overcome the limitations of CALIOP observations during Arctic summer - like that of Di Pierro et al. (2013), who introduced a detection rate for correction - are likely to produce incorrect data or will at the very least overemphasize the few data available during 
summer. Nevertheless, it is worth proceeding with our study for the limited number of available cases in order to assess the value of the combined data sets.

\subsection{HYSPLIT trajectories}

We use the HYSPLIT (Hybrid Single-Particle Lagrangian Integrated Trajectory; Draxler and Rolph, 2010) model of the NOAA Air Resources Laboratory to study the advection of air parcels to and from Zeppelin station. Forward and backward trajectories with time intervals of $1 \mathrm{~h}$ were calculated starting and arriving every $3 \mathrm{~h}$ at the height and location of Zeppelin station, respectively.

Meteorological parameters from the Global Data Assimilation System (GDAS) are provided along the trajectories and are used in this study to estimate $\mathrm{RH}$ at the location of the CALIPSO overpass.

\section{Comparison approach}

Anderson et al. (2003) and Kovacs (2006) investigated the regional representativeness of local measurements of atmospheric aerosols by correlating these to the distance at which coincident satellite observations were performed. They concluded that the distances at which two measurements, both at ambient RH, along a trajectory show acceptable correlation to establish a connection are 300 and $500 \mathrm{~km}$ for observations over land and sea sites, respectively. As a result of these earlier studies, we considered a region from 0 to $25^{\circ} \mathrm{E}$ and from 75 to $82^{\circ} \mathrm{N}$ for this study. CALIPSO passed over this area 2018 times in 2008. The closest overpass occurred only $2 \mathrm{~km}$ away from Zeppelin station, while the furthest one was at a distance of $360 \mathrm{~km}$.

We started our investigation by applying the closestapproach method to link CALIPSO observations in the region of interest to coincident dry in situ measurements at Zeppelin station. While this course of action led to a high number of matches, it did not enable reasonable case-by-case reconciliation of in situ and remote-sensing data. Differences in the compared aerosol optical properties ranged between 2 and 3 orders of magnitude. Perpetual refinement of the comparison procedure as described below showed that the failure in reconciling the different observations in the initial comparison is due to the following:

1. physically meaningless comparison scenarios in which no connection can be established between the locations of the ground site and the satellite track during heterogeneous aerosol conditions,

2. the inclusion of apparently unrealistic signal spikes in the CALIOP extinction coefficient in the case of fixed or inappropriately selected along-track averaging intervals,

3. humidification effects,
4. the temporal delay in the observations.

The first two points make reasonable comparisons impossible. The latter two can still introduce uncertainties of up to $100 \%$.

Differences in exact location of the measurements pose a severe problem, since the humidity and aerosol content of air is highly variable in time and space (horizontally and vertically). Thus, it is essential to select that part of the CALIPSO ground track for which it is most likely that both CALIOP and in situ instrumentation actually sampled the same air mass. Following the approach presented in Tesche et al. (2013), air-mass trajectories are used to connect the in situ station to the segment of the CALIPSO ground track that is most likely to lead to a physically meaningful comparison. The length of the trajectories between Zeppelin station and the intersection with the CALIPSO ground track provides us with the time lag between fitting observations. This trajectory matching allows for items 1 and 4 on the list above to be addressed.

Screening of the CALIPSO data is a major effort in obtaining meaningful comparison cases. Our case-by-case investigation shows that profiles fulfilling the quality assurance criteria given in Sect. 2.3.1 can still contain data points that are obviously unrealistic and could be due to the low SNR of the observation or improper cloud screening. Though such points have little impact when comparing highly averaged data, they dominate individual comparisons. Here, we selected overpasses that in fact show extinction coefficients (i.e., signals above the CALIOP detection threshold) in a height range from 250 to $730 \mathrm{~m}$ that spans around the height of Zeppelin station. This holds for $24 \%$ of all overpasses in the area of interest. Next, we discarded cases for which trajectories starting every $3 \mathrm{~h}$ at Zeppelin for $15 \mathrm{~h}$ after and before an overpass, respectively, did not cross the CALIPSO ground track. This left $9 \%$ of all 2018 overpasses in 2008. Note that in contrast to Anderson et al. (2003) and Kovacs (2006), who referred to the length scale, we use a timescale and restrict the comparison to a time delay of $15 \mathrm{~h}$. This corresponds to a maximum distance of $360 \mathrm{~km}$ at a mean transport velocity of about $7 \mathrm{~m} \mathrm{~s}^{-1}$. We believe that time rather than distance is a better parameter to assess changes in the aerosol properties in the atmosphere. The majority of the track segments for comparison were located either in the vicinity or to the north (beyond $81^{\circ} \mathrm{N}$ ) of the ground site (not shown).

Finally, we checked for the availability of (1) CALIOP extinction coefficients at the intersection of satellite ground track and air-mass trajectories and (2) humidified extinction coefficients at Zeppelin station at the time of the CALIPSO overpass plus/minus the lag provided by the trajectories. That was the case for only 57 individual overpasses (3\% of all 2018 overpasses) in 2008, which form the core of this study. The extinction coefficients from CALIOP were averaged in the vicinity of the crossing point of the ground track and the trajectory. The along-track averaging range was determined 
individually for each overpass according to the spread of the crossing trajectories with different start times. A change in the along-track average of the CALIOP extinction profile to a fixed interval can result in large differences in the resulting mean extinction profile during heterogeneous conditions or physically meaningless comparison scenarios. Once an extinction profile could be obtained at the proper location for comparison, the values in the height range from 250 to $730 \mathrm{~m}$ (eight $60 \mathrm{~m}$ height bins) were averaged. We chose this height range to account for vertical motions during the transport from the location of the CALIOP observation to Zeppelin station (backward trajectories) or vice versa (forward trajectories). For particular cases, better agreement with the in situ observation may be obtained for an average over a smaller height range. However, we chose a conservative range that was found to be suitable for the majority of cases considered in this study. The average and the corresponding standard deviation (as a measure of vertical homogeneity) represent values used in the comparison to the findings of the measurements at Zeppelin station. To coarsely account for uncertainties in the trajectories, in situ extinction coefficients were averaged over $5 \mathrm{~h}$ (five $1 \mathrm{~h}$ values) centered around the time when the in situ instruments sampled the same air parcels as CALIOP, i.e., time of a CALIPSO overpass plus the time lag determined from the length of the trajectories that connect this overpass to Zeppelin station.

\section{Results and discussion}

The time period of 22 to 28 January 2008 has been chosen to illustrate the analytical work and some of the results obtained. Figure 3 presents the dry scattering coefficient measured with the nephelometer at Zeppelin station and the ambient extinction coefficients derived as described in Sects. 2.2.1 and 2.2.2 during this period. The ambient $\mathrm{RH}$ given in the figure reflects the influence of hygroscopicity, which causes the huge differences between dry scattering and ambient extinction values. The latter parameter was not estimated when ambient RH exceeded values of $95 \%$. The time period covered in Fig. 3 shows 10 CALIPSO overpasses that were connected to the ground station with the help of trajectories (see symbols and corresponding numbers at the top of Fig. 3). Extinction coefficients extracted from the CALIPSO observations could be compared to ground-based measurements for six cases (overpasses 1, 2, 3, 6, 8, and 9). Four examples of how trajectories are used to connect the ground site with the proper segment of the CALIPSO track (overpasses 1, 6, 8, and 10) are given in the lower part of Fig. 3. Triangles mark cases for which aerosol profiles were obtained during cloud-free conditions, as indicated by a cloud optical thickness (COT) of zero. The examples of overpasses 1 and 8 show how the trajectories lead to a cloud-free part of the ground track. The different lengths and tracks of the trajectories indicate that time and distance should not be considered synonymous. The satellite- and ground-based extinction coefficients agree within their error bars for the overpasses on 22 and 27 January 2008, with the shortest time delay of $6 \mathrm{~h}$ (201 km distance) and the longest time delay of $15 \mathrm{~h}(322 \mathrm{~km}$ distance). Note that ambient RH was above $90 \%$ on 22 January 2008 and that the difference between the dry scattering coefficient and the RH-corrected extinction coefficient is as much as a factor of 10. A much smaller ratio of ambient to dry extinction coefficients can be found for 26 and 27 January 2008 , for which RH varies between 65 and $90 \%$. The cases in Fig. 3 illustrate the importance of accounting for the proper time delay between the measurements of CALIOP and in situ instrumentation. Using the in situ measurements at the time of the satellite overpass increases the ratio of the ambient extinction coefficients from in situ and CALIOP observations by $30 \%$ for the example cases in Fig. 3 .

Using the trajectories as described above, a cloudy part of the CALIPSO ground track $(\mathrm{COT}>0, \mathrm{AOT}=0)$ was identified for the overpasses $4,5,7$, and 10 . No comparisons could be performed since there is no aerosol information available for these cases. This kind of situation inhibited comparisons in 127 cases for the months January to April and October to December 2008. Typical scenarios are as follows: no height bins are marked as containing aerosols at all, all aerosols are located above or below our height range of interest, or the obtained aerosols profile is of unreasonable shape and/or magnitude.

For overpass 6 in Fig. 3, aerosol information was obtained in cloudy environment $(\mathrm{COT}>0, \mathrm{AOT}>0)$. Even though this overpass occurred only $21 \mathrm{~km}$ from the ground site, the CALIPSO observation is in disagreement with the result of the in situ measurement. This emphasizes that using a closest approach for comparison of ground-based measurements and CALIPSO observations might not always be the best choice. The case also illustrates that even few clouds can disturb aerosol measurements with spaceborne lidar. Note also that trajectories might actually lead to a track segment that is not closest to the ground site, as is the case for overpass 8 .

Finally, 57 cases of the 2018 overpasses in 2008 were suitable for comparing extinction coefficients from CALIOP observations and humidified ground-based measurements (Fig. 4). Even though CALIOP extinction coefficients are generally larger than the ones derived from the in situ measurements, most comparisons can be reconciled to a factor of 1 to 5, with the majority not exceeding a factor of 2. This is a surprisingly good finding considering the data processing that is necessary to come up with comparable quantities. According to the color coding of the points in Fig. 4, there is no indication that a closer distance between satellite ground track and in situ ground site (or a smaller time lag, not shown) would lead to a better outcome of the reconciliation procedure. Successful reconciliation actually occurs for many cases associated with overpasses at larger distances from the ground site. These cases would not have been included in this study if we had chosen a distance in 

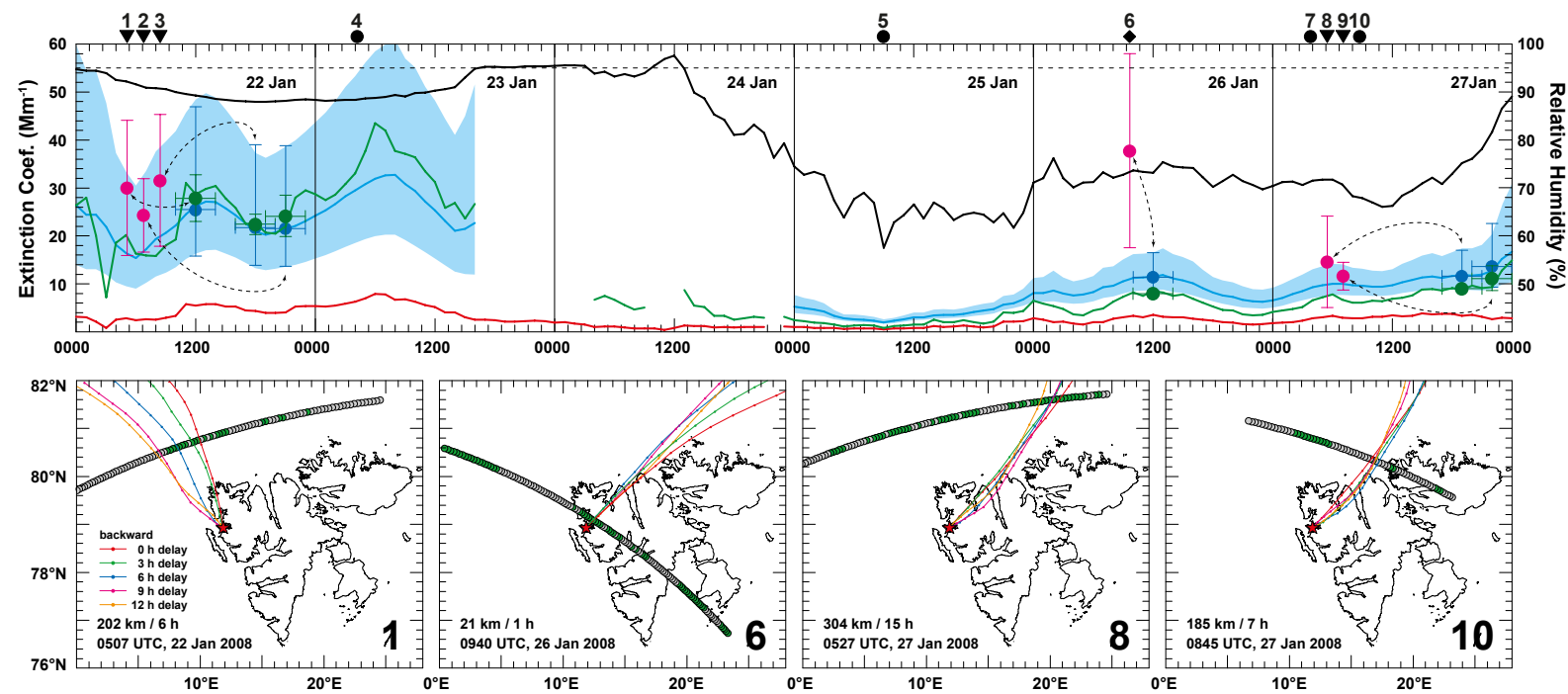

Figure 3. Upper panel: CALIPSO extinction coefficient $(532 \mathrm{~nm}$, magenta circles) compared to in situ measurements of the dry scattering coefficient (550 nm, red line) and the ambient extinction coefficient determined from the measurements of DMPS (550 nm, green line) and nephelometer plus PSAP (550 nm, blue line) for the time period of 22 to 27 January 2008. The blue shaded area marks the region of possible values based on the minimum and maximum estimates of the $\gamma$ value. Green and blue circles mark $5 \mathrm{~h}$ averages of the ambient extinction coefficients from the in situ observations. Arrows show which values are compared. Ambient RH is given in black. Values above RH $>95 \%$ were disregarded (dashed black line). Symbols and corresponding numbers mark CALIPSO overpasses that could be connected to the ground site for the considered time period: only aerosol features (triangles), aerosol and cloud features (diamond), and no or only cloud features (circles). Lower panel: presentation of the use of trajectories to connect the in situ site to the spaceborne measurements for four selected cases (marked as 1, 6, 8, and 10 in the upper plot). The CALIPSO ground track is marked by gray (no aerosol data available) and green (aerosol data available) circles, which refer to individual $5 \mathrm{~km}$ aerosol profiles. Colored dots and lines mark backward trajectories starting close to the CALIPSO overpass (red) as well as $3 \mathrm{~h}$ (green), $6 \mathrm{~h}$ (blue), $9 \mathrm{~h}$ (magenta), and $12 \mathrm{~h}$ (orange) after the overpass. The time of overpass is given in the respective plots. The red star marks the location of Zeppelin station.

range rather than time for comparison. This suggests that the method of comparing local point or column-integrated measurements to the closest-approach observation of CALIPSO is likely to yield misleading results.

We performed a deeper analysis of the factors that could explain why a difference of as large as a factor of 5 occurs for some of the cases included here. Besides the spatial distance and temporal delay between the observations, we considered the relative humidity at Zeppelin station and at the crossing point of the satellite ground track and trajectories, the occurrence of clouds and rain along the trajectory, and the wind direction at the ground site. However, only the latter parameter could be linked to the outliers in Fig. 4. Figure 5a shows that the largest absolute difference in the ambient extinction coefficients from CALIOP and in situ measurements occurs during westerly flow. It could be that aerosol conditions are more stable for air masses approaching Zeppelin station from the north and via ice-covered ocean compared to the open water to the west. On the other hand, the CALIOP aerosol classification scheme can choose from a larger pool of lidar ratios for observations over ocean and land compared to those over snow and ice (Omar et al., 2009). Hence, we investigated the dominant aerosol type selected in the CALIPSO data retrieval for the individual comparisons. It was found that the most characteristic outliers in Figs. 4 and 5a occur for cases that were identified predominantly as polluted dust or polluted continental. These aerosol types are rather uncommon at $78^{\circ} \mathrm{N}$ and suggest misclassification in the CALIPSO retrieval. Misclassification can occur as a result of signal noise, improper cloud screening, or due to surface effects. Given the structure of the CALIPSO aerosol classification scheme described in Omar et al. (2009), CALIOP observations in the Svalbard region during background conditions (weakly depolarizing and integrated attenuated backscatter coefficient not exceeding the threshold value of 0.0015 at $532 \mathrm{~nm}$ ) should be classified as clean continental (over land and snow/ice) and clean marine (over ocean).

Clean continental aerosol was classified for most comparison cases (see color coding in Fig. 5a) and seems to be the most appropriate choice. In addition, classifying aerosol features as polluted dust or smoke (lidar ratio of $65-70 \mathrm{sr}$ ) instead of clean continental aerosol (lidar ratio of $35 \mathrm{sr}$ ) will only result in a factor-of- 2 difference, while the disagreement we obtain in our comparison for cases classified as something other than clean continental and clean marine shows factors in the range of 0.62 to 11.23 with a median of 4.03 . The range is 0.26 to 5.72 with a median of 1.36 for cases classified as clean continental or clean marine. 


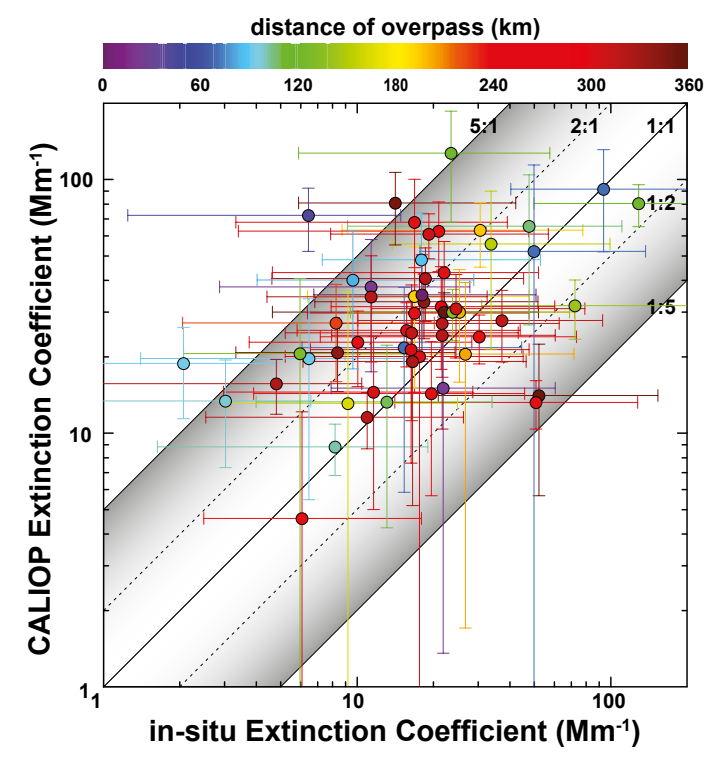

Figure 4. Comparison of the ambient $550 \mathrm{~nm}$ extinction coefficient from humidification of nephelometer and PSAP measurements (see Sect. 2.2.2) vs. the ambient $532 \mathrm{~nm}$ extinction coefficient extracted from CALIPSO overpasses for 57 suitable cases. The color coding describes the distance of the CALIPSO observation from the ground site. Error bars refer to the results of using the lower and upper estimate in the $\gamma$ value for humidification and the standard deviation from averaging over nine $60 \mathrm{~m}$ CALIPSO height bins between 250 and $730 \mathrm{~m}$, respectively. Ratios of $1: 1,1: 2$, and $1: 5$ are marked by solid and dashed lines and the shaded area.

Strong variation in $\mathrm{RH}$ between the location of the CALIPSO ground track and Zeppelin station could also cause the scatter of values presented in Fig. 4. Such RH differences have a direct effect on the scattering enhancement factor $f(\mathrm{RH})$ and thus the difference between dry and ambient extinction coefficients. The scattering enhancement factor was found to be much higher for Arctic aerosol compared to observations at continental, background, or marine sites (Zieger et al., 2013). Consequently, we should expect that even small differences in RH between the measurements at Zeppelin and along the satellite track can lead to high differences in the ambient extinction coefficient. This holds especially for high $\mathrm{RH}>85 \%$. We investigated whether we can find a connection between the difference in $\mathrm{RH}(\Delta \mathrm{RH})$ at the two measurement locations (i.e., the CALIOP ground-track segment and Zeppelin station) and the agreement in the comparison of ambient extinction coefficients at those sites. The $\mathrm{RH}$ at the location of the CALIOP observation is taken from the meteorological data provided with the trajectory analysis and is thus highly uncertain. For the 57 cases considered, the $\Delta \mathrm{RH}$ showed a mean value of $12 \pm 10 \%$ (mean $\mathrm{RH}$ of $80 \pm 12 \%$ at Zeppelin station) with a maximum value of around $30 \%$ (not shown). Though $\Delta \mathrm{RH}$ was considerable for several cases, we could not establish whether this factor or the resulting difference in $f(\mathrm{RH})$ can fully explain the

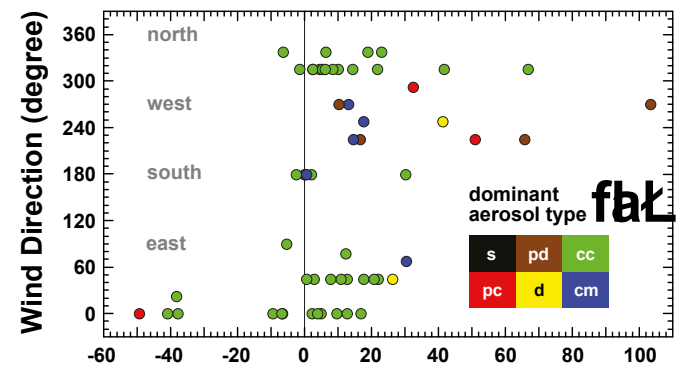

Abs. Diff. in Extinction Coefficient ( $\left.\mathrm{Mm}^{-1}\right)$

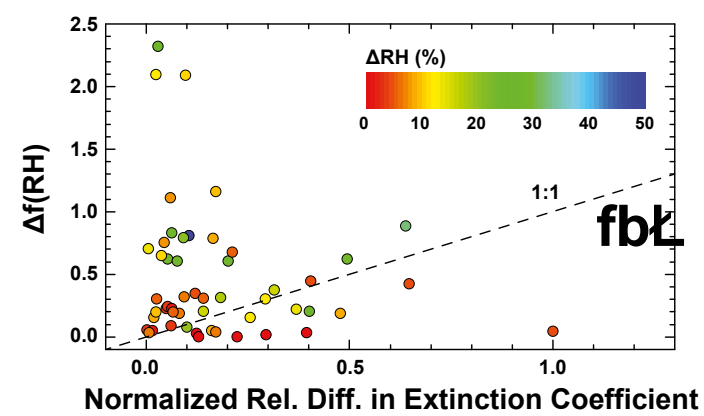

Figure 5. Detailed view of (a) the effect of wind direction on the absolute difference in the ambient extinction coefficients derived from observations at Zeppelin and by CALIOP and (b) the connection between the relative difference $\Delta f(\mathrm{RH})$ of the scattering enhancement factors at Zeppelin station and at the intersection of trajectories and CALIPSO ground track and the relative difference in the ambient extinction coefficients observed at the two locations. The color coding refers to the dominant aerosol type identified in the CALIOP observations ( $\mathrm{cm}$ - clean marine; $\mathrm{d}$ - dust; $\mathrm{pc}$ - polluted continental; cc - clean continental; pd - polluted dust; s - smoke, not observed) and the difference in RH observed at Zeppelin station and taken from the trajectory calculations at the location of the CALIPSO overpass, respectively. The dashed line marks the $1: 1$ line.

disagreement found in the ambient extinction coefficients. Figure $5 b$ shows the connection between the relative difference in $f(\mathrm{RH})$ at the locations of CALIOP and in situ observations and the relative difference in the ambient extinction coefficients obtained from these observations. If hygroscopic growth were the only factor necessary to consider in our comparison, values should align along the $1: 1$ line. Deviations are likely to be related to the observation of different air masses at the two locations or the improper representation of meteorological parameters in the trajectory model.

Table 1 gives a detailed overview of the results obtained from the comparison of spaceborne and ground-based observations subdivided according to the months of 2008 and whether cloud-free or cloudy CALIOP aerosol profiles were used in the comparison. For the 57 considered cases, Table 1 shows that time delay is rather evenly distributed between 0 and $15 \mathrm{~h}$ with a median of $8 \mathrm{~h}$. Of the 57 suitable cases, $39 \mathrm{oc}-$ curred during most favorable cloud-free conditions (AOT $>$ $0, \mathrm{COT}=0$ ), while the remaining 18 cases represent cloudy 
Table 1. Results of the comparison of CALIPSO observations and in situ measurements at Zeppelin station (ambient 1 and 2 as in Fig. 1) subdivided according to months of the year 2008 and cloud-free and cloudy conditions in the CALIPSO aerosol profiles. The first line (columns 3-7) refers to mean values and standard deviation, while the second line refers to median and range of values.

\begin{tabular}{|c|c|c|c|c|c|c|}
\hline \multirow[t]{2}{*}{ Month } & \multirow{2}{*}{$\begin{array}{l}\text { Number } \\
\text { of cases }\end{array}$} & \multirow{2}{*}{$\begin{array}{l}\text { Distance } \\
(\mathrm{km})\end{array}$} & \multirow{2}{*}{$\begin{array}{l}\text { Delay } \\
\text { (h) }\end{array}$} & \multicolumn{3}{|c|}{ Extinction coefficient $\left(\mathrm{Mm}^{-1}\right)$} \\
\hline & & & & ambient 1 & ambient 2 & CALIPSO \\
\hline \multirow[t]{2}{*}{ January } & 14 & $223 \pm 112$ & $8.9 \pm 4.5$ & $15.6 \pm 7.5$ & $15.5 \pm 10.2$ & $27.4 \pm 10.5$ \\
\hline & & $271,21-343$ & $9.5,1.0-15.0$ & $17.6,1.2-27.8$ & $17.0,2.1-25.4$ & $26.9,11.5-48.2$ \\
\hline \multirow[t]{2}{*}{ February } & 11 & $251 \pm 110$ & $7.8 \pm 4.3$ & $12.0 \pm 4.4$ & $19.2 \pm 12.6$ & $23.5 \pm 15.9$ \\
\hline & & $288,2-357$ & $9.0,0.0-15.0$ & $12.8,3.0-18.0$ & $16.6,4.8-52.2$ & $19.1,4.6-63.2$ \\
\hline \multirow[t]{2}{*}{ March } & 10 & $223 \pm 111$ & $9.8 \pm 4.1$ & $21.2 \pm 12.1$ & $30.1 \pm 22.3$ & $42.1 \pm 21.2$ \\
\hline & & $252,44-360$ & $9.0,3.0-15.0$ & $17.4,4.0-43.01$ & $26.3,6.4-51.0$ & $36.5,13.2-72.3$ \\
\hline \multirow[t]{2}{*}{ April } & 10 & $216 \pm 104$ & $8.5 \pm 3.6$ & $35.9 \pm 27.5$ & $34.8 \pm 20.1$ & $59.9 \pm 32.6$ \\
\hline & & $203,69-352$ & $9.0,3.0-13.0$ & $27.7,13.8-95.9$ & $23.7,14.2-94.0$ & $58.3,27.1-127.0$ \\
\hline \multirow[t]{2}{*}{ October } & 2 & $292 \pm 40$ & $7.5 \pm 0.7$ & $6.0 \pm 1.7$ & $10.7 \pm 6.6$ & $28.6 \pm 8.3$ \\
\hline & & $292,263-320$ & $7.5,7.0-8.0$ & $6.0,4.8-7.2$ & $10.7,10.1-11.4$ & $28.6,22.8-34.5$ \\
\hline \multirow[t]{2}{*}{ November } & 8 & $128 \pm 66$ & $5.9 \pm 3.2$ & $16.3 \pm 24.6$ & $26.7 \pm 17.3$ & $24.8 \pm 23.2$ \\
\hline & & $107,23-226$ & $5.5,1.0-12.0$ & $7.1,1.6-75.7$ & $8.8,3.0-130.0$ & $17.4,8.8-80.3$ \\
\hline \multirow[t]{2}{*}{ December } & 2 & $106 \pm 33$ & $6.5 \pm 3.5$ & $4.2 \pm 1.6$ & $7.8 \pm 4.7$ & $30.3 \pm 13.8$ \\
\hline & & $106,82-129$ & $6.5,4.0-9.0$ & $4.2,3.1-5.3$ & $7.8,6.0-9.6$ & $30.3,20.5-40.1$ \\
\hline \multirow[t]{2}{*}{ All year } & 57 & $212 \pm 107$ & $8.2 \pm 4.0$ & $18.8 \pm 17.8$ & $23.3 \pm 15.4$ & $34.7 \pm 23.7$ \\
\hline & & $242,2-360$ & $8.0,0.0-15.0$ & $14.3,1.2-95.9$ & $20.7,2.1-130.0$ & $27.8,4.6-127.0$ \\
\hline \multirow[t]{2}{*}{ Cloudy } & 18 & $178 \pm 116$ & $6.2 \pm 3.9$ & $23.0 \pm 25.2$ & $28.6 \pm 17.9$ & $35.4 \pm 20.9$ \\
\hline & & $169,2-323$ & $5.5,0.0-13.0$ & $14.7,1.2-95.9$ & $17.9,2.1-130.0$ & $30.5,14.3-91.6$ \\
\hline \multirow[t]{2}{*}{ Cloud free } & 39 & $228 \pm 100$ & $9.2 \pm 3.7$ & $16.9 \pm 13.0$ & $20.8 \pm 14.2$ & $34.4 \pm 25.2$ \\
\hline & & $247,23-360$ & $9.0,1.0-15.0$ & $14.3,1.6-74.9$ & $18.0,3.0-72.6$ & $27.2,4.6-127.0$ \\
\hline
\end{tabular}

comparisons $(\mathrm{AOT}>0$, COT $>0$ ). Resolving the comparison according to cloudiness in the CALIPSO observations (not shown) leads to ambiguous results: for 7 of the 18 cloudy cases $(39 \%)$ a difference larger than a factor of 2 is found between the extinction coefficients from CALIOP and Zeppelin station, while for the cloud-free cases 17 out of $39(44 \%)$ exceed this difference. The average time delay is $9.2 \pm 3.8 \mathrm{~h}$ for cloud-free cases, while it is only $6.2 \pm 3.9 \mathrm{~h}$ for cloudy cases. Accordingly, cloud-free cases show a mean distance of $228 \pm 100 \mathrm{~km}$ and cloudy ones $178 \pm 116 \mathrm{~km}$. Extinction coefficients from CALIPSO vary between 4.6 and $127.0 \mathrm{Mm}^{-1}$ for cloud-free cases, while the range of values for cloudy profiles is much narrower and only spans from 14.3 to $91.6 \mathrm{Mm}^{-1}$

\section{Summary and conclusions}

This study presents a comparison of extinction coefficients as determined from spaceborne lidar (CALIOP) measurements and from ground-based in situ measurements at Zeppelin station, Ny-Ålesund, Svalbard, during the year 2008. To obtain meaningful comparison, we had to consider several issues:

1. Neither in situ instruments nor spaceborne lidar (CALIOP) provide us with direct measurements of the ambient aerosol extinction coefficient.
2. Approved methods were used to obtain ambient extinction coefficients from dry in situ measurements performed with commonly used instruments.

3. Extinction coefficients from the spaceborne sensor were taken from operational CALIPSO products that underwent elaborate calibration and quality assurance.

4. Air-mass trajectories were used to ensure that comparisons were performed for the same air mass. They allow a connection to be established between the satellite's ground track and Zeppelin station and the alongtrack averaging intervals to be adapted according to the spatial spread of the crossing trajectories. The averaging height range of $510 \mathrm{~m}$ centered at the elevation of the ground site was chosen to account for vertical displacement during travel along the trajectories. Temporal averaging of ground-based data of $5 \mathrm{~h}$ further mitigates imprecision in the trajectory output.

The detailed matching procedure used in this study reduced the number of comparison cases from over 2000 overpasses in 2008 to 57 overpasses during 42 days of that year. Even though it is a costly and elaborate case-by-case comparison, it is likely to yield more significant results than what is obtained by comparing monthly means of surface measurements with monthly regional means of CALIOP observations. However, since averaging times of only a few 
hours were applied in this study, we cannot draw conclusions about what will happen if the length of the temporal averaging window is increased. The median ambient extinction coefficient for the 57 comparison cases was $27.8 \mathrm{Mm}^{-1}$ for the CALIOP data compared to values of 14.3 and $20.7 \mathrm{Mm}^{-1}$ derived from in situ measurements of the particle size distribution and dry scattering coefficients, respectively. The different humidity during the measurement in the atmosphere and within a laboratory is an ever-present limitation for studies like the one presented here. The thermodynamic state (e.g., $\mathrm{RH}$ ) of the samples and the assumptions on the hygroscopic properties for the in situ measurements are therefore vital factors for a successful comparison of aerosol extinction coefficients. In the case of our study, results are also influenced by the CALIPSO aerosol model that is required for the extinction-coefficient retrieval, the CALIOP feature detection limit, and the criteria that are used to match satellite observations to the measurement at the ground site.

Detailed knowledge of the humidity field is of vital importance when relating in situ measurements to observations with spaceborne sensors. The effect of relative humidity on the light-scattering properties of aerosol particles in the atmosphere is the dominant obstacle for a systematic reconciliation of measurements of the two platforms. Additional problematic factors in the allocation procedure applied in this study were unfavorable wind direction (no intersection between trajectories and ground track), presence of clouds (RH $>95 \%$ at Zeppelin station and/or no aerosol information from CALIOP), no data from Zeppelin station or CALIOP, and the CALIOP detection threshold that prevents reliable aerosol detection in the presence of sunlight. CALIOP detects almost no aerosol features in the Svalbard region during Arctic summer even though the tropospheric median AOT is generally larger than 0.05 at visible wavelengths during May and June (Tomasi et al., 2007, 2012; Glantz et al., 2014). This is in agreement with the study by Di Pierro et al. (2013), which investigated the distribution of aerosols in the Arctic from CALIOP measurements. Consequently, CALIOP data have to be treated with great caution when they are used for studies of aerosol occurrence rate, transport patterns, radiative effects, and interactions with clouds under background conditions during polar day.

Based on the study presented here we also conclude that consolidating data sets that are averaged over large areas and/or long time periods can lure us into a sense of false confidence, whereas in fact there may actually be weak or no connection between individual observations. Using highly averaged parameters in the deduction of scientific findings is of particular importance for the validation of model simulations. Consequently, special emphasis should be placed on proper selection of temporal and spatial averaging intervals when attempting to use spaceborne lidar observations in connection with ground-based measurements and model outputs.
Acknowledgements. CALIOP data used in this study were obtained from the NASA Langley Research Center Atmospheric Science Data Center (http://eosweb.larc.nasa.gov). We thank Birgitta Noone and Tabea Hennig for maintaining the in situ instruments at Zeppelin station. The Swedish Environmental Agency and Stockholm University are acknowledged for long-term support of the observations at Zeppelin station. We also acknowledge the support within CLIMSLIP. Paul Zieger was supported by a postdoc fellowship of the Swiss National Science Foundation (grant no. P300P2_147776).

Edited by: A. Petzold

\section{References}

Anderson, T. and Ogren, J.: Determining aerosol radiative properties using the TSI 3563 integrating nephelometer, Aerosol Sci. Tech., 29, 57-96, 1998.

Anderson, T. L., Charlson, R. J., Winker, D. M., Ogren, J. A., and Holmén, K.: Mesoscale variations of tropospheric Aerosols, J. Atmos. Sci., 60, 119-136, 2003.

CALIPSO Users Guide (2012), Lidar Level $25 \mathrm{~km}$ Cloud and Aerosol Profile Products, available at: http://www-calipso.larc.nasa.gov/resources/calipso_users_ guide/data_sum-maries/profile_data.php, last access: 6 February 2014.

Covert, D. S. and Heintzenberg, J.: Size distributions and chemical properties of aerosol at Ny-Ålesund, Svalbard, Atmos. Environ. 27, 2989-2997, 1993.

Di Pierro, M., Jaeglé, L., Eloranta, E. W., and Sharma, S.: Spatial and seasonal distribution of Arctic aerosols observed by the CALIOP satellite instrument (2006-2012), Atmos. Chem. Phys., 13, 7075-7095, doi:10.5194/acp-13-7075-2013, 2013.

Draxler, R. R. and Rolph, G. D.: HYSPLIT (HYbrid Single-Particle Lagrangian Integrated Trajectory) Model access via NOAA ARL READY Website (http://ready.arl.noaa.gov/HYSPLIT. php), NOAA Air Resources Laboratory, Silver Spring, MD, 2010.

Eleftheriadis, K., Vratolis, S., and Nyeki, S.: Aerosol black carbon in the European Arctic: Measurements at Zeppelin station, Ny-Ålesund,Svalbard from 1998-2007, Geophys. Res. Lett., 36, L02809, doi:10.1029/2008GL035741, 2009.

Eneroth, K., Kjellström, E., and Holmén, K.: A trajectory climatology for Svalbard; investigating how atmospheric flow patterns influence observed tracer concentrations, Phys. Chem. Earth, 28, 1191-1203, doi:10.1016/j.pce.2003.08.051, 2003.

Glantz, P., Bourassa, A. E., Herber, A., Iversen, T., Karlsson, J., Kirkevåg, A., Maturilli, M., Seland, Ø., Stebel, K., Struthers, H., Tesche, M., and Thomason, L.: Remote sensing of aerosols in the Arctic for an evaluation of global climate model simulations, J. Geophys. Res., 119, 8169-8188, doi:10.1002/2013JD021279, 2014.

Herber, A., Thomason, L. W., Gernandt, H., Leiterer, U., Nagel, D., Schulz, K.-H., Kaptur, J., Albrecht, T., and Notholt, J.: Continuous day and night aerosol optical depth observations in the Arctic between 1991 and 1999, J. Geophys. Res., 107, AAC 6-1-ACC 6-13, doi:10.1029/2001JD000536, 2002.

Hoff, R., Guise-Bagley, L., Staebler, R. M., Wiebe, H. A., Brook, J., Georgi, B., and Düsterdiek, T.: Lidar, nephelometer, and in situ 
aerosol experiments in southern Ontario, J. Geophys. Res., 101, 19199-19209, doi:10.1029/95JD03228, 1996.

Hoffmann, A., Ritter, C., Stock, M., Shiobara, M., Lampert, A., Maturilli, M., Orgis, T., Neuber, R., and Herber, A.: Ground-based lidar measurements from Ny-Ålesund during ASTAR 2007, Atmos. Chem. Phys., 9, 9059-9081, doi:10.5194/acp-9-9059-2009, 2009

Hoffmann, A., Osterloh, L., Stone, R., Lampert, A., Ritter, C., Stock, M., Tunved, P., Hennig, T., Böckmann, C., Li, S.-M., Eleftheriadis, K., Maturilli, M., Orgis, T., Herber, A., Neuber, R., and Dethloff, K.: Remote sensing and in-situ measurements of tropospheric aerosol, a PAMARCMiP case study, Atmos. Environ., 52, 56-66, doi:10.1016/j.atmosenv.2011.11.027, 2012.

Kovacs, T.: Comparing MODIS and AERONET aerosol optical depth at varying separation distances to assess ground-based validation strategies for spaceborne lidar, J. Geophys. Res., 111, D24203, doi:10.1029/2006JD007349, 2006.

Kreidenweis, S. M., Koehler, K., DeMott, P. J., Prenni, A. J., Carrico, C., and Ervens, B.: Water activity and activation diameters from hygroscopicity data - Part I: Theory and application to inorganic salts, Atmos. Chem. Phys., 5, 1357-1370, doi:10.5194/acp-5-1357-2005, 2005.

Mauritsen, T., Sedlar, J., Tjernström, M., Leck, C., Martin, M., Shupe, M., Sjogren, S., Sierau, B., Persson, P. O. G., Brooks, I. M., and Swietlicki, E.: An Arctic CCN-limited cloud-aerosol regime, Atmos. Chem. Phys., 11, 165-173, doi:10.5194/acp-11165-2011, 2011.

Masonis, S., Ansmann, A., Müller, D., Althausen, D., Ogren, J. A., Jefferson, A., and Sheridan, P. J.: An intercomparison of aerosol light extinction and $180^{\circ}$ backscatter as derived using in situ instruments and Raman lidar during the INDOEX field campaign, J. Geophs. Res., 107, INX2 13-1-INX2 13-21, doi:10.1029/2000JD000035, 2002.

Müller, D., Ansmann, A., Mattis, I., Tesche, M., Wandinger, U., Althausen, D., and Pisani, G.: Aerosol-type-dependent lidar ratios observed with Raman lidar, J. Geophys. Res., 112, D16202, doi:10.1029/2006JD008292, 2007.

Omar, A. H., Winker, D. M., Vaughan, M. A., Hu, Y., Trepte, C. R., Ferrare, R. A., Lee, K.-P., and Hostetler, C. A.: The CALIPSO automated aerosol classification and lidar ratio selection algorithm, J. Atmos. Ocean. Tech., 26, 1994-2014, doi:10.1175/2009JTECHA1231.1, 2009.

Petters, M. D. and Kreidenweis, S. M.: A single parameter representation of hygroscopic growth and cloud condensation nucleus activity, Atmos. Chem. Phys., 7, 1961-1971, doi:10.5194/acp-71961-2007, 2007.

Rastak, N., Silvergren, S., Zieger, P., Wideqvist, U., Ström, J., Svenningsson, B., Maturilli, M., Tesche, M., Ekman, A. M. L., Tunved, P., and Riipinen, I.: Seasonal variation of aerosol water uptake and its impact on the direct radiative effect at Ny-Ålesund, Svalbard, Atmos. Chem. Phys., 14, 7445-7460, doi:10.5194/acp14-7445-2014, 2014.

Skupin, A., Ansmann, A., Engelmann, R., Baars, H., and Müller, T.: The Spectral Aerosol Extinction Monitoring System (SAE'MS): setup, observational products, and comparisons, Atmos. Meas. Tech., 7, 701-712, doi:10.5194/amt-7-701-2014, 2014.

Stock, M., Ritter, C., Herber, A., von Hoyningen-Huene, W., Baibakov, K., Gräser, J., Orgis, T., Treffeisen, R., Zinoviev, N., Makshtas, A., and Dethloff, K.: Springtime Arctic aerosol:
Smoke versus haze, a case study for March 2008, Atmos. Environ., 52, 48-55, doi:10.1016/j.atmosenv.2011.06.051, 2012.

Stock, M., Ritter, C., Aaltonen, V., Aas, W., Handorff, D., Herber, A., Treffeisen, R., and Dethloff, K.: Where does the optically detectable aerosol in the European Arctic come from?, Tellus B, 66, 21450, doi:10.3402/tellusb.v66.21450, 2014.

Ström, J., Umegård, J., Tørseth, K., Tunved, P., Hansson, H.C., Holmén, K., Wismann, V., Herber, A., and König-Langlo, G.: One year of particle size distribution and aerosol chemical composition measurements at the Zeppelin station, Svalbard, March 2000 - March 2001, Phys. Chem. Earth, 28, 1181-1190, doi:10.1016/j.pce.2003.08.058, 2003.

Tang, I. N. and Munkelwitz, R. H.: Aerosol Phase Transformation and Growth in the Atmosphere, J. Appl. Meteorol., 33, 791-796, 1994.

Tang, I. N.:, Chemical and size effects of hygroscopic aerosols on light scattering coefficients, J. Geophys. Res., 101, 1924519250, doi:10.1029/96JD03003, 1996.

Tesche, M., Wandinger, U., Ansmann, A., Müller, D., Althausen, D., and Omar, A. H.: Ground-based validation of CALIPSO observations of dust and smoke in the Cape Verde region, J. Geophys. Res., 118, 2889-2902, doi:10.1002/jgrd.50248, 2013.

Tomasi, C., Vitale, V., Lupi, A., Di Carmine, C., Campanelli, M., Herber, A., Treffeisen, R., Stone, R. S., Andrews, E., Sharma, S., Radionov, V., von Hoyningen-Huene, W., Stebel, K., Hansen, G. H., Myhre, C. L., Wehrli, C., Aaltonen, V., Lihavainen, H., Virkkula, A., Hillamo, R., Ström, J., Toledano, C., Cachorro, V. E., Ortiz, P., de Frutos, A. M., Blindheim, S., Frioud, M., Gausa, M., Zielinski, T., Petelski, T., and Yamanouchi, T.: Aerosols in polar regions: A historical overview based on optical depth and in situ observations, J. Geophys. Res., 112, D16205, doi:10.1029/2007JD008432, 2007.

Tomasi C., Lupi, A., Mazzola, M., Stone, R. S., Dutton, E. G., Herber, A., Radionov, V. F., Holben, B. N., Sorokin, M. G., Sakerin, S. M., Terpugova, S. A., Sobolewski, P. S., Lanconelli, C., Petkov, B. H., Busetto, M., and Vitale, V.: An update on polar aerosol optical properties using POLAR-AOD and other measurements performed during the International Polar Year, Atmos. Environ., 52, 29-47, doi:10.1016/j.atmosenv.2012.02.055, 2012.

Tunved, P., Ström, J., and Krejci, R.: Arctic aerosol life cycle: linking aerosol size distributions observed between 2000 and 2010 with air mass transport and precipitation at Zeppelin station, Ny-Ålesund, Svalbard, Atmos. Chem. Phys., 13, 3643-3660, doi:10.5194/acp-13-3643-2013, 2013.

Winker, D. M., Vaughan, M. A., Omar, A. H., Hu, Y., Powell, K. A., Liu, Z., Hunt, W. H., and Young, S. A.: Overview of the CALIPSO mission and CALIOP data processing algorithms, J. Atmos. Ocean. Tech., 26, 2310-2323, doi:10.1175/2009JTECHA1281.1, 2009.

World Meteorological Organization: Aerosol measurement procedures guidelines and recommendations, GAW Report No. 153, World Meteorological Organization Global Atmosphere Watch, Geneva, Switzerland, 2003.

Young, S. A. and Vaughan, M. A.: The retrieval of profiles of particulate extinction from Cloud-Aerosol Lidar Infrared Pathfinder Satellite Observations (CALIPSO) data: Algorithm description, J. Atmos. Ocean. Tech., 26, 1105-1119, doi:10.1175/2008JTECHA1221.1, 2009 
Zieger, P., Fierz-Schmidhauser, R., Gysel, M., Ström, J., Henne, S., Yttri, K. E., Baltensperger, U., and Weingartner, E.: Effects of relative humidity on aerosol light scattering in the Arctic, Atmos. Chem. Phys., 10, 3875-3890, doi:10.5194/acp-10-38752010, 2010.

Zieger, P., Weingartner, E., Henzing, J., Moerman, M., de Leeuw, G., Mikkilä, J., Ehn, M., Petäjä, T., Clémer, K., van Roozendael, M., Yilmaz, S., Frieß, U., Irie, H., Wagner, T., Shaiganfar, R., Beirle, S., Apituley, A., Wilson, K., and Baltensperger, U.: Comparison of ambient aerosol extinction coefficients obtained from in-situ, MAX-DOAS and LIDAR measurements at Cabauw, Atmos. Chem. Phys., 11, 2603-2624, doi:10.5194/acp11-2603-2011, 2011.

Zieger, P., Kienast-Sjögren, E., Starace, M., von Bismarck, J., Bukowiecki, N., Baltensperger, U., Wienhold, F. G., Peter, T., Ruhtz, T., Collaud Coen, M., Vuilleumier, L., Maier, O., Emili, E., Popp, C., and Weingartner, E.: Spatial variation of aerosol optical properties around the high-alpine site Jungfraujoch (3580 m a.s.1.), Atmos. Chem. Phys., 12, 7231-7249, doi:10.5194/acp12-7231-2012, 2012.
Zieger, P., Fierz-Schmidhauser, R., Weingartner, E., and Baltensperger, U.: Effects of relative humidity on aerosol light scattering: results from different European sites, Atmos. Chem. Phys., 13, 10609-10631, doi:10.5194/acp-13-10609-2013, 2013.

Ziemba, L. D., Thornhill, K. L., Ferrare, R., Barrick, J., Beyersdorf, A. J., Chen, G., Crumeyrolle, S. N., Hair, J., Hostetler, C., Hudgins, C., Obland, M., Rogers, R., Scarino, A. J., Winstead, E. L., and Anderson, B. E.: Airborne observations of aerosol extinction by in situ and remote-sensing techniques: Evaluation of particle hygroscopicity, Geophys. Res. Lett., 40, 417-422, doi:10.1029/2012GL054428, 2013. 